\title{
Model Disiplin Kerja, Iklim Organisasi dan Produktivitas Kerja Pegawai
}

\author{
Zulfikar Ikhsan', Suwatno2, Budi Santoso \\ ${ }^{1}$ SMK Darunnajah Boarding School, Bogor, Indonesia \\ ${ }^{2}$ Program Studi Pendidikan Ekonomi, Sekolah Pasca Sarjana, Universitas Pendidikan Indonesia, Bandung, Indonesia \\ ${ }^{3}$ Program Studi Pendidikan Manajemen perkantoran, FPEB. Universitas Pendidikan Indonesia, Bandung, Indonesia \\ 1Zulfikarikhsan666@student.upi.edu, 2suwatno@upi.edu, budisantoso@upi.edu
}

\begin{abstract}
Demands for productivity are getting higher. The tight competition among retailers causes companies that do not have high productivity to compete. Quality of HR is the key to success. The purpose of the study was to obtain an explanation of the influence of work discipline and organizational climate on the work productivity of employees at PT. Surya Donasin Regional Office Cianjur, which numbered 59 employees randomly selected. The research method uses explanatory survey with multiple linear regression analysis. Based on the results of the research that productivity as one of the keys to compete in the retail industry is determined by work discipline and organizational climate that supports work productivity. Labor productivity is determined by internal and external dynamics in the form of organizational climate. The managerial implication is that the lack of productivity over employees causes low company productivity. Increase productivity as an option to support work productivity.
\end{abstract}

Keywords : Work discipline; organizational climate; productivity; retailer industry

\begin{abstract}
Abstrak
Tuntutan terhadap produktivitas semakin tinggi. Persaingan yang cukup ketat diantara perusahaan retailer menyebabkan perusahaan yang tidak memiliki produktivitas tinggi kalah bersaing. Kualitas SDM menjadi kunci keberhasilan. Tujuan penelitian untuk memperoleh penjelasan tentang pengaruh disiplin kerja dan iklim organisasi terhadap produktivitas kerja para pegawai di PT. Surya Donasin Regional Office Cianjur yang berjumlah 59 pegawai yang dipilih secara acak. Metode penelitian menggunakan survey explanatory dengan analisis regresi linear berganda. Berdasarkan hasil penelitian bahwa produktivitas sebagai salah satu kunci untuk bersaing dalam industri retail ditentukan oleh disiplin kerja dan iklim organisasi yang mendukung produktivitas kerja. Produktivitas tenaga kerja ditentukan oleh dinamika internal dan eksternal berupa iklim organisasi. Implikasi manajerial adalah lemahnya produktivitas pegawai menyebabkan produktivitas perusahaan rendah. Meningkatkan produktivitas sebagai pilihan untuk mendukung produktivitas kerja.
\end{abstract}

Kata Kunci: Disiplin kerja; iklim organisasi; produktivitas; industri retailer

\section{PENDAHULUAN}

Inovasi teknologi membentuk masa depan industri dan ketenagakerjaan menjadi lebih produktif. Perkembangan tersebut perlu diikuti dengan kesiapan SDM mengikuti perkembangan teknologi. disisi lain Era globalisasi ekonomi dengan perkembangan teknologi pesat berpengaruh pada persaingan dan kelangsungan hidup perusahaan. Perusahaan memerlukan ketersediaan Sumber daya manusia (SDM) dengan tanggung jawab dan dedikasi tinggi sebagai kunci untuk mewujudkan visi dan misi perusahaan. Perusahaan memerlukan dukungan sumber daya manusia yang handal agar memenangkan persaingan yang semakin ketat.

Aspek penting yang menjadi fokus perusahan adalah produktivitas yang dihasilkan dari SDM. Menurut Organisasi Perburuhan Internasional (2017) dijelaskan bahwa masih terdapat pekerja dalam jumlah besar yang bekerja di pekerjaan dengan produktivitas rendah. Menurut Sulaeman (2014) menjelaskan produktivitas sebagai aspek penting guna menunjang keberhasilan tujuan 
organisasi. Produktivitas tinggi yang ditunjukan para pegawai menguntungkan perusahaan maupun karyawannya dalam bentuk kompensasi. Produktivitas menggambarkan etos kerja, sikap mental maupun karakteristik psikologisnya.

Menurut Singadimedjo yang dikutip Sutrisno (2009) menjelaskan konsep produktivitas secara umum sebagai perbandingan hasil (output) dengan penggunaaan sumber daya (input). Input antara lain tenaga kerja, dan output diukur berdasarkan kesatuan fisik, bentuk dan nilai (Sutrisno, 2009). Produktivitas karyawan berkaitan dengan tujuan perusahaan (Senen, 2013). Upaya organisasi dalam meningkatkan produktivitas dapat dilihat dari bekerjanya struktur dan fungsi manajer. Fuanida (2001) menjelaskan adanya hubungan antara disiplin kerja pada produktivitas karyawan. Hal senada juga dikemukakan oleh Elqadri et. al (2015) bahwa disiplin kerja terbukti berdampak pada produktivitas kerja secara signifikan. Karna disiplin kerja dapat meningkatkan produktivitas kerja.

Interaksi antar individu dan lingkungannya turut menentukan bagaimana aktivitas dan perilaku produktifnya. Iklim organisasi sangat penting untuk menjelaskan produktivitas kerja pegawai. Iklim organisasi sebagai hal yang nyata yang dirasakan oleh orang-orang yang ada didalam suatu organisasi. Iklim organisasi menentukkan produktivitas kerja.

Produktivitas kerja pegawai tidak dapat dilepaskan dari struktur pembagian kerja. Struktur tersebut menjelaskan tanggung jawab individu, tim, maupun lembaga secara keseluruhan. Komunikasi vertikal maupun horizontal, penghargaan terhadap sumber daya manusia. kompensasi maupun sangsi yang diterapkan yang adil menggambarkan bagaimana iklim yang ada. Seperti dikemukakan Yee Poh Li \& Mahadevan (2018) bahwa Iklim organisasi dapat dipandang sebagai ide ilustratif yang mencerminkan pandangan reguler dan pemahaman semua individu sehubungan dengan berbagai komponen organisasi, misalnya, struktur, kerangka kerja, dan praktik. Oleh karena itu, iklim organisasi pada dasarnya menyinggung pengalaman karyawan dalam organisasi. Gilmer
(1961) mengemukakan iklim organisasi menggambarkan adanya pembeda suatu organisasi dengan organisasi lainnya. Iklim organisasi mempengaruhi tingkah laku individu dalam organisasi.

Produktivitas tidak selalu dapat dicapai dengan optimal seperti di PT. Surya Donasin Regional Office Cianjur. Hasil analisis data menunjukan ada trend penurunan produktivitas pada pegawai bagian penjualan. Pada tahun 2017 rata-rata produktivitas para pegawai bagian penjualan adalah $75 \%$ dari target. Selain fenomena tentang produktivitas, hasil observasi dan catatan disiplin para pegawai masih belum sesuai yang diharapkan.

Data sepanjang tahun 2017 menunjukan secara keseluruhan penggunaan jam kerja di PT. Surya Donasin Regional Office Cianjur masih belum efektif dan efesien. Waktu istirahat dan toleransi keterlambatan lebih banyak dari yang ditetapkan oleh perusahaan. Pada saat aktivitas pekerjaan sangat sibuk hanya $30 \%$ yang bersedia pulang lebih lambat atau datang lebih awal 30 menit. Tingkat kehadiran lebih awal hanya $55 \%$. Tepat waktu $20 \% .25 \%$ pegawai pulang lebih awal dan hanya $10 \%$ yang pulang lebih lambat untuk menyelesaikan pekerjaan.

Fenomena lain yang ditemukan berdasarkan hasil observasi adalah terkait dengan apa yang dirasakan oleh para pegawai dalam lingkungan kerjanya. Rata-rata kurang dari $50 \%$ pegawai yang mampu bertahan dalam situasi yang berat terutama di akhir bulan. Para pegawai yang yakin dengan mampu menghadapi kondisi kerja yang dinamis dan bertekanan tinggi dalam tuntutan pekerjaan kurang dari setengah dari jumlah total pegawai dan sebagian besar para senior yang memiliki pengalaman lebih dari 3 tahun bekerja. Semangat kerja pegawai dalam menjalani setiap aktivitas organisasi terutama diakhir bulan sangat rendah dengan tingkat aktivitas cukup tinggi.

Kondisi tersebut diduga berkaitan dengan produktivitas yang rendah. Sejalan dengan Suwatno (2005) yang menjelaskan tentang kedudukan SDM (sumber daya manusia) sebagai pondasi bagi terciptanya produktivitas kerja. Produktivitas kerja pegawai yang rendah bagi perusahaan tetap menjadi persoalan tersendiri. 
Masalah produktivitas kerja dinilai sebagai masalah aktual yang penting untuk dijelaskan. Menurut Yuniarsih dan Suwatno (2016) mengemukakan produktivitas erat kaitannya dengan sumberdaya (inefisiensi) dan target. Hal ini sesuai dengan pendapat Fryer et. al (2012) dalam penelitiannya yang mengatakan bahwa produktivitas tenaga kerja mempengaruhi kinerja industri. Karena tenaga kerja merupakan bagian besar dari biaya proyek dan diperlukan untuk dimanfaatkan secara efektif.

Penelitian ini bertujuan untuk memperoleh penjelasan pengaruh disiplin kerja dan iklim organisasi terhadap produktivitas kerja pegawai PT. Surya Donasin Regional Office Cianjur.

\section{KERANGKA PENELITIAN \& HIPOTESIS}

\section{Disiplin Kerja}

Disiplin kerja sebagai sikap kerja yang diperlukan guna mendukung tercapainya tujuan. Disiplin erat kaitannya dengan upaya perusahaan untuk meningkatkan kinerja serta tujuan perusahaan. Disiplin adalah suatu ketaatan yang sungguh-sungguh yang didukung oleh kesadaran untuk menjalankan tugas dan kewajibannya serta berperilaku yang seharusnya berlaku didalam lingkungan tertentu. Simamora (2004) mengatakan bahwa disiplin sebagai sejumlah prosedur yang dijadikan alat untuk mengoreksi atau memberikan sangsi bagi pegawai yang indisipliner. Rivai dan Ella (2011) menyatakan bahwa disiplin sebagai alat komunikasi untuk mengubah suatu perilaku. Disiplin pegawai berkaitan dengan kesadaran reflektif pegawai terhadap peraturan yang ditetapkan. Hasibuan (2009) menjelaskan "tingkat disiplin sebagai kesadaran dan kesediaan menaati peraturan perusahaan dan norma-norma sosial yang berlaku. Sinambela (2012) menjelaskan disiplin sebagai kemampuan kerja secara teratur, tekun, sesuai dengan aturan-aturan yang berlaku. Sutrisno (2009) mengungkapkan disiplin sebagai perilaku seseorang sesuai peraturan dan prosedur kerja. Disiplin adalah pernyataan evaluatif, tingkah laku, yang berkaitan dengan peraturan dari organisasi baik tertulis maupun yang tidak tertulis.
Siswanto (2005) menjelaskan tentang faktor-faktor dari disiplin kerja itu adalah kehadiran, kewaspadaan, ketaatan pada standar kerja, ketaatan pada peraturan kerja, etika kerja. Rivai (2009) menjelaskan tingkat kehadiran, ketaatan pada peraturan kerja, standar kerja, tingkat kewaspadaan tinggi, dan etis sebagai indikator disiplin. Pada dasarnya disiplin terkait dengan standar kerja, prosedur termasuk etika kerja yang melandasi perilaku pegawai di tempat kerja.

\section{Iklim Organisasi}

Iklim organisasi menggambarkan mengenai kondisi yang dirasakan oleh individu dalam organisasi. Tagiuri dan Litwin (Wirawan, 2007) menjelaskan iklim sebagai sesuatu yang dialami atau dirasakan oleh anggota organisasi. Iklim organisasi mempengaruhi perilaku individu. Gibson (1996) menjelaskan iklim organisasi sebagai seperangkat atribut yang melekat pada suatu lingkungan kerja yang diamati dan dirasakan baik secara langsung maupun tidak langsung oleh karyawan. Iklim dianggap sebagai kekuatan yang besar dalam mempengaruhi tingkah laku kerja. Davis dan Newstroom (2001) menyatakan bahwa "iklim organisasi sebagai karateristik atau kepribadian organisasi. Iklim organisasi membedakan organisasi dengan organisasi lain berdasarkan persepsi masing anggota organisasi. Isaksen et. al (2001) menjelaskan iklim organisasi sebagai ciri organisasi dilihat berdasarkan pola perilaku, sikap, dan perasaan berulang oleh individu dalam organisasi. Lunenburg dan Ornstein (1991), Gilmer (1961) menjelaskan iklim organisasi mempengaruhi perilaku orang-orang yang berada dalam organisasi. Biyantu (2007) menyatakan sebagai persepsi individu terhadap pola perilaku orang.

Wirawan (2007) menjelaskan terdapat tujuh dimensi iklim organisasi yaitu lingkungan fisik, sosial, pelaksanaan sistem manajemen, produk, konsumen yang dilayani, kondisi fisik dan aspek kejiwaan anggota organisasi, dan budaya organisasi. Robert Stringer (dalam Wirawan, 2007) menjelaskan indikasi iklim organisasi yaitu struktur, standar, tanggung jawab, penghargaan, support, dan komitmen. Iklim organisasi adalah sejumlah atribut yang melekat pada ruang 
dimana organisasi berada yang dirasakan oleh individu dalam organisasi.

\section{Produktivitas}

Tujuan utama manajemen sumber daya manusia yaitu menciptakan sistem pemberdayaan personil untuk kinerja produktif baik kuantitas maupun kualitas. Tingkat produktivitas setiap pegawai bisa tinggi maupun rendah. Produktivitas menggambarkan sikap moral tentang kehidupan yang lebih baik (Ravianto, 2003). Yuniarsih dan Suwatno (2016) mengungkapkan produktivitas sebagai hasil kongkrit (produk) individu ataupun kelompok yang dihitung berdasarkan satuan waktu. Ravianto (2003) mengungkapkan bahwa secara umum produktivitas antara keluaran (output) yang dihasilkan oleh berbagai elemen masukan (input), dibagi dengan masukan itu sendiri yang digunakan untuk menghasilkan keluarankeluaran. Roghanian et. al (2012) menjelaskan bahwa produktivitas sebagai konsep sosial dan diperkenalkan sebagai "attitude of mind". Ini mencari untuk memperbaiki hal-hal yang sudah ada secara terus-menerus dan menekankan bahwa seseorang dapat melakukan lebih baik di hari ke hari membandingkan hari sebelumnya, dengan kata lain setiap hari menjadi lebih baik.

Menurut Yuniarsih dan Suwatno (2016) Produktivitas diukur dengan produktivitas fisik dan produktivitas nilai. Paul Mali (Nanang Fattah, 1999) menjelaskan efisiensi dan efektivitas sebagai ukuran produktivitas. Gaspers (Yuniarsih dan Suwatno, 2016) menjelaskan produktivitas diukur dengan memperbandingkan antara output dengan input.

\section{Hipotesis}

Perwujudan sikap mental produktif dalam berbagai kegiatan dipengaruhi oleh peningkatan disiplin. Hal ini berdasarkan data yang menunjukkan bahwa ketaatan terhadap standar kerja berpengaruh terhadap kuantitas dan kualitas kerja pegawai. Oleh karena itu disiplin kerja harus terus dipertahankan dan ditingkatkan agar produktivitas kerja pegawai dapat dipertahankan dan dapat meningkat semakin menjadi lebih baik pula dari waktu ke waktu. Sastrohadiwiryo (2005), Fuanida (2001) $\begin{array}{lccr}\text { menjelaskan } & \text { pengaruh } & \text { disiplin } & \text { terhadap } \\ \text { produktivitas } & \text { kerja. } & \text { Pertiwi } & \text { (2017) }\end{array}$ menambahkan adanya pengaruh disiplin kerja terhadap produktivitas kerja. Sutrisno (2009) menjelaskan disiplin mendorong karyawan mengikuti berbagai standar dan aturan. Hipotesis yang diajukan adalah disiplin kerja berpengaruh positif terhadap produktivitas kerja pegawai PT. Surya Donasin Regional Office Cianjur.

Produktivitas tidak dapat dilepaskan dari iklim yang dirasakan pegawai. Suasana kerja yang kondusif memungkinkan pegawai bekerja secara produktif. Pemahaman pegawai tentang tugas (job description), posisi, tugas-tugas tambahan, tanggung jawab, atau pemecahan masalah, koordinasi secara formal, maupun interaksi yang harus diikuti pegawai dalam organisasi. Rahimic (2013) mengatakan iklim organisasi mempengaruhi produktivitas, inovasi dan kepuasan karyawan. Zamzam dan Romli (2017) mengemukakan iklim organisasi memengaruhi produktivitas kerja. Organisasi merujuk pada suasana internal organisasi yang dirasakan secara langsung, maupun tidak langsung oleh anggotanya. Iklim organisasi diasumsikan berpengaruh pada produktivitas kerja. Hipotesis kedua adalah iklim organisasi berpengaruh positif terhadap produktivitas kerja pegawai PT. Surya Donasin Regional Office Cianjur.

\section{METODE PENELITIAN}

Metode dalam penelitian ini bersifat deskriptif dan eksplanasi. Berdasarkan jenis penelitian deskriptif, metode dalam penelitian ini adalah survey explanatory. Populasi di dalam penelitian ini adalah pegawai PT. Surya Donasin Regional Office Cianjur bagian penjualan (sales) yang berjumlah 70 orang. Jumlah sampel adalah 59 yang dipilih secara acak. Setelah semua angket yang sebelumnya telah diuji valid dan reliable, mengolah dan menganalisis data angket dengan alat bantu SPSS 23. Analisis data regresi linear berganda (Multiple Regression).

\section{HASIL DAN PEMBAHASAN}

Karakteristik pegawai baik ditingkat pendidikan, pengalaman maupun usia cukup beragam. $64 \%$ laki-laki dan $36 \%$ atau sejumlah 
21 pegawai adalah perempuan. Hampir setengah responden berusia 26 - 30 Tahun yaitu $41 \%$. Di Bawah 20-25 Tahun sebesar $39 \% .14 \%$ pegawai berusia diantara 31 - 35 Tahun. $3 \%$ atau sebanyak 2 orang berusia 36 s.d 40 tahun dan diatas 40 tahun. 24 responden mulai bekerja pada 5 tahun yang lalu, sebanyak 18 responden atau $31 \%$ bekerja mulai 6 s.d 10 tahun yang lalu. 13 responden atau $22 \%$ bekerja mulai 11 s.d 15 tahun yang lalu. Hanya sebagian kecil yang bekerja diatas 16 tahun yaitu 4 pegawai. sebagian responden memiliki pendidikan SMP adalah 1 pegawai, $22 \%$ berpendidikan SMU/SMK, sebanyak 32 responden atau $19 \%$ pegawai berpendidikan D3, 17 responden atau $29 \%$ berpendidikan $\mathrm{SI}$.

Kondisi disiplin, iklim organisasi dan produktivitas para pegawai cukup beragam. Rata-rata tingkat disiplin berada pada kelompok sedang yaitu berada pada skor 3.41 dengan standar deviasi 0.40 . Iklim organisasi yaitu, 3.7 dengan standar deviasi 0.355 , produktivitas berada pada tingkat sedang dengan skor 3.44 dengan standar deviasi 0.42. Rata-rata berada pada kelompok sedang dibandingkan dengan skor ideal. Dilihat dari standar deviasi diperoleh gambaran kesenjangan tertinggi adalah 0.42 .

Berdasarkan hasil penelitian menunjukan bahwa data berdistribusi normal. Sebaran data berada disekitar garis lurus diagonal. Nilai DW adalah 1.170. Berdasarkan nilai $\mathrm{DW}_{\text {tabel }}(\mathrm{K}-2, \mathrm{n}=59)$ maka disimpulkan Tidak ada masalah autokorelasi. $d_{L}<d<4-d_{u}$. Hasil Collinearity statistics bahwa nilai VIF menunjukan tidak terjadi gejala multikolinearitas antara variabel independen. Hasil Pengamatan pada gambar Scatterplot menunjukan varians dari residual tidak berpola /acak, Satu pengamatan ke pengamatan lain tidak sama.

Berdasarkan hasil uji anava dengan menggunakan bantuan SPSS.23 diperoleh hasil sebagai berikut disiplin memiliki pengaruh signifikan terhadap produktivitas. hubungan antara disiplin $\left(\mathrm{X}_{1}\right)$ dan produktivitas $(\mathrm{Y})$ adalah sebesar 0,818 . Artinya berpengaruh sebesar $67 \%$ dengan nilai signifikansi 0.00 . Nilai $F$ sebesar 56.764 artinya dapat dijadikan sebagai model yang dapat memprediksi variabel produktivitas. Iklim organisasi memiliki pengaruh signifikan terhadap produktivitas. Nilai signifikansi 0.032 , dan pengaruhnya terhadap produktivitas sebesar $24 \%$. Nilai F hitung 17.837. Iklim organisasi dapat memprediksi produktivitas.

Dari tabel koefisien Persamaan regresinya adalah pada model $Y=0.264+0,696 X_{1}+0.204 X_{2}$. Hasil pengujian menunjukan nilai signifikansi 0.005 . Hal ini dapat dilihat dari nilai signifikannya lebih rendah dari derajat kekeliruan alpha yaitu 0.05. Maka keputusannya ho ditolak dan menerima ha. Disiplin dan iklim memiliki pengaruh signifikan terhadap produktivitas baik secara parsial maupun secara simultan

Manajer tidak hanya fokus pada upaya untuk mengintegrasikan fungsi sistem pengelolaan SDM seperti disiplin kerja melalui SOP (standar operational procedure). Manajer mengoptimalkan fungsi dukungan lingkungan yang berorientasi pada manfaat "utilitas" pegawai bagi organisasi dengan tetap memperhatikan bagaimana feedback perusahaan bagi pegawai. Produktivitas adalah sebuah proses yang didukung oleh aktivitas bisnis yang diidentifikasi memiliki keunggulan baik dari sisi biaya maupun dari sisi efektifnya. Identifikasi keunggulan mulai dari input sampai dengan output dituangkan dalam bentuk prosedur aktivitas bisnis. Kegiatan-kegiatan individu sesuai dengan prosedur mendorong aktivitas bisnis menjadi lebih efektif dan efisien guna menghasilkan produktivitas. Aktivitas individu didorong oleh pemahaman yang lebih baik sesuai dengan SOP. Identifikasi aktivitas yang unggul yang dituangkan dalam bentuk prosedur diikuti karyawan dan menjadi landasan aktivitas. Dukungan iklim lingkungan mampu mengantisipasi terjadinya penolakan terhadap upaya-upaya perubahan yang berorientasi pada produktivitas. Orientasi produktif menjadikan lingkungan mengarahkan pegawai dalam melaksanakan fungsi dan perannya meningkatkan produktivitas.

Hasil penelitian sejalan dengan penelitian yang menjelaskan tentang pengaruh disiplin terhadap produktivitas kerja seperti Sastrohadiwiryo (2005), Fuanida (2001) menjelaskan pengaruh disiplin terhadap Produktivitas Kerja. Pertiwi (2017), Sutrisno (2009) menambahkan adanya pengaruh disiplin kerja terhadap produktivitas kerja. Hasil penelitian diperkuat oleh hasil penelitian Rahimic 
(2013) yang mengatakan iklim organisasi mempengaruhi produktivitas, inovasi dan kepuasan karyawan. Zamzam dan Romli (2017) mengemukakan iklim organisasi memengaruhi produktivitas kerja. Hasil penelitian secara bersama-sama menunjukan adanya pengaruh signifikan.

Berdasarkan hasil penelitian tersebut maka keberhasilan untuk meningkatkan produktivitas terletak pada optimalisasi fungsi disiplin dan peningkatan iklim organisasi yang mendorong disiplin. Fungsi-fungsi SDM baik dari rekruitmen, penempatan pegawai, pelatihan, evaluasi kinerja dan system kompensasi, hubungan industrial maupun system pemutusan hubungan kerja didasarkan pada kedua konsep tersebut. Sebagai contoh dalam pelatihan maupun system kompensasi ditekankan pada disiplin dan peningkatan iklim organisasi yang positif. Hubungan industrial seperti serikat pekerja berorientasi pada berkembangnya iklim organisasi yang mendorong produktivitas termasuk bagaimana system pemutusan hubungan kerja karyawan. Disiplin dan iklim organisasi melekat pada fungsi-fungsi SDM agar menghasilkan produktivitas tinggi.

\section{KESIMPULAN}

Disiplin kerja dan iklim organisasi dapat memprediksi perubahan pada produktivitas kerja para pegawai di PT. Surya Donasin Regional Office Cianjur baik itu secara simultan maupun parsial. Implikasi manajerial adalah lemahnya produktivitas pegawai yang menyebabkan produktivitas perusahaan rendah. Meningkatkan produktivitas sebagai pilihan untuk mendukung produktivitas kerja.

\section{DAFTAR PUSTAKA}

Alan, Lawler. (2000). Productivity Improvement Manual. England: Gower Publishing Company Limited.

Biyantu. (2007). Manajemen Pembelajaran (Studi Tentang Pengaruh Kinerja Kepala Sekolah, Iklim Kerja Guru, Penghasilan Guru dan Teknologi Pembelajaran Terhadap Kinerja Guru dan Kualitas
Belajar Siswa Sekolah Menengah Pertama (SMP) Negeri di Kota Pekanbaru. Disertasi Universitas Pendidikan Indonesia. Bandung: Tidak Diterbitkan.

Davis, Keith \& Newstrom, John W. (2001). Perilaku Dalam Organisasi. Jilid 1 terjemahan. Jakarta: Erlangga.

Elqadri, Z. M., Wardoyo, D. T. W., \& -, P. (2015). The Influence of Motivation and Discipline Work against Employee Work Productivity Tona'an Markets. Review of European Studies, 7(12), 59-66. https://doi.org/10.5539/res.v7n12p59

Fattah, Nanang. (1996). Landasan Manajemen Pendidikan. Bandung: PT Remaja Rosdakarya.

Fuanida, A. (2001). Pengaruh pelatihan, disiplin kerja, dan motivasi terhadap produktivitas kerja karyawan CV. Sapu Dunia Semarangf. Jurnal IImu Administrasi Bisnis, 1-12.

Fryer, K., Antony, J., \& Ogden, S. (2012). International Journal of Productivity and Performance Management. International Journal of Productivity and Performance Management Iss Measuring Business Excellence Iss International Journal of Public Sector Management, 54(6), 551-567. https://doi.org/10.1108/026567102104 15703

Gibson, James. (1996). Organisasi dan Manajemen. Jakarta: Erlangga.

Gilmer, B. Van Haller. (1961). Industrial Psychology 2nd Edition. New york: McGraw-Hill, Inc.

Hasibuan, Malayu S.P. (2009). Manajemen Sumber Daya Manusia. Jakarta: Bumi Aksara.

ILO. (2017). Indonesia Jobs Outlook 2017: Harnessing technology for growth and job creation/International Labour Office - Jakarta: ILO, 2017 xii, 76 p.

Isaksen, S. G., Lauer, K. J., Ekvall, G., \& Britz, A. (2001). Perceptions of the Best and Worst Climates for Creativity: Preliminary Validation Evidence for the Situational Outlook Questionnaire. 
Creativity Research Journal, 13(2), 171184

https://doi.org/10.1207/S15326934CRJ1 302_5

Lunenburg, C. Fred and Allan C. Ornstein. (1991). Educational Administration Concept and Practice. Belmont-California: Wadsworth Publishing Company.

Pertiwi, F. (2017). Pengaruh Disiplin Kerja terhadap Produktivitas Kerja Pegawai Negeri Sipil di Kantor Dinas Perindustrian Perdagangan Koperasi dan UMKM Provinsi Kalimantan Timur. Jurnal Administrasi Negara, 5(1), 5360-5374.

Rahimic, Z. (2013). Influence of Organizational Climate on Job Satisfaction in Bosnia and Herzegovina Companies. International Business Research, 6(3), 129-139. https://doi.org/10.5539/ibr.v6n3p129

Ravianto J. (2003). Produktivitas dan Manusia Indonesia. Jakarta: SIUP.

Rivai, Veithzal \& Ella Jauvani S. (2009). Manajemen Sumber Daya Mansuia Untuk Perusahaan. Jakarta: PT Raja Grafindo Persada.

Rivai, Veithzal \& Ella Jauvani S. (2011). Manajemen Sumber Daya Mansuia Untuk Perusahaan Dari Teori ke Praktik. Jakarta: Rajawali Pers.

Roghanian, P., Rasli, A., \& Gheysari, H. (2012). Productivity Through Effectiveness and Efficiency in the Banking Industry. Procedia - Social and Behavioral Sciences, 40, 550-556. https://doi.org/10.1016/j.sbspro.2012.0 3.229

Sastrohadirwiryo, Bedjo S. (2005). Manajemen Tenaga Kerja Indonesia, Pendekatan Administratif dan Operasional. Jakarta: Bumi Aksara

Senen, S. H. siti. (2013). Pengaruh Motivasi Kerja dan Kemampuan Kerja Karyawan terhadap Produktivitas Kerja Karyawan Pada PT. Safilindo Permata. Jurnal Strategic Pendidikan Manajemen Bisnis, 7(September), 1-15.

Simamora, Henry. (2004). Manajemen Sumber Daya Manusia. Yogyakarta: STIE YKPN
Sinambela, Lijan Poltak. (2012). Kinerja Pegawai Teori Pengukuran dan Implikasi. Yogyakarta: Graha Ilmu.

Siswanto, Bedjo. (2005). Pengantar Manajemen. Jakarta: Bumi Aksara.

Sulaeman, A. (2014). Pengaruh Upah dan Pengalaman Kerja terhadap Produktivitas Karyawan Kerajinan Ukiran Kabupaten Subang. Trikonomika, 13(1), 91-100.

Sutrisno, Edy. (2009). Manajemen Sumber Daya Manusia. Jakarta: Kencana.

Suwatno. (2005). Pengaruh Penempatan terhadap Produktivitas Kerja Pegawai Administrasi. Jurnal Manajemen \& Sistem Informasi. FPEB UPI. Vol.3, No.6, Jan 2005.

Wirawan. (2007). Budaya dan Iklim Organisasi, Teori dan Aplikasi Dan Penelitian. Jakarta. Salemba Empat.

Yee Poh Li, \& Mahadevan, A. (2018). a Study on the Impact of Organisational Change on It Employees. International Journal of Accounting \& Business Management, 7(8), $1-5$. https://doi.org/10.9780/2249894X

Yuniarsih, Tjuju \& Suwatno. (2016). Manajemen Sumber Daya Manusia. Bandung. Alfabeta.

Zamzam, Fakhry., Romli, A Roni. (2017). Analisis Pengaruh Iklim Organisasi Terhadap Kinerja Dan Produktivitas Legislasi Daerah Provinsi Sumatera Selatan. Jurnal Media Wahana Ekonomika, Vol. 14, No.2, Juli 2017 : 56-64. 